\title{
Un panorama del estatus actual del maya yucateco escrito*
}

\author{
Michal Brody
}

Entre los idiomas indígenas de México, el maya yucateco (maaya) presenta un caso único. Su escritura ha existido por más de un milenio; se escribía con glifos antes de la llegada de los europeos, y por cinco siglos ha empleado grafías del alfabeto latino. En las últimas décadas, la cultura y el idioma, así como su escritura, han gozado de una revalorización social. El artículo presenta una vista panorámica del estatus actual del maaya escrito, analiza su situación y especula sobre su desarrollo futuro. La alfabetización dual (español-maya) generalmente no se percibe como algo primordial o deseable. Muchas publicaciones actuales están orientadas a una audiencia de aprendices, y están dentro del marco del español. Sin embargo, hay motivos para pensar que la escritura maaya florecerá y prosperará.

PALABRAS CLAVE: sociolingüística, escritura, maya yucateco, idiomas indígenas, ideologías lingüísticas

Among the indigenous languages of México, Yucatec Maya (Maaya) is a unique case. Maaya writing has existed for more than a millennium-written with glyphs before the arrival of the Europeans, and with graphs of the Latin alphabet since then. In the last decades, the language and culture -as well as the written language — have enjoyed a new social appreciation. This paper presents an overview of the current status of written Maaya, analyzes its situation, and speculates about its future development. Despite its recent appreciation, Maaya/Spanish biliteracy is generally not perceived as essential or highly desirable. Significantly, many current publications are written for an audience of beginners and within the framework of Spanish. However, there are reasons to expect that Maaya writing will flourish and prosper.

KEYWORDS: sociolinguistics, writing, yucatec maya, indigenous languages, linguistic ideologies

\author{
MICHAL BRODY: Universidad de Oriente, Valladolid, Yucatán. \\ michalbrody@gmail.com
}

Desacatos, núm. 23, enero-abril 2007, pp. 275-288.

Recepción: 17 de agosto de 2005 / Aceptación: 3 de octubre de 2005

Traducción: Miguel Güémez Pineda y Michal Brody.

\footnotetext{
* Una versión anterior de este artículo fue parte de mi tesis de doctorado, The Fixed Word, the Moving Tongue: Variation in Written Yucatec Maya and the Meandering Path Toward Unified Norms (Universidad de Texas, Austin, 2004). Mis agradecimientos a Miguel Güémez Pineda de la Universidad Autónoma de Yucatán por la traducción, y a Mucuy Kak Moó Marín por sus comentarios.
} 
E ntre los idiomas indígenas de la República mexicana, el maya yucateco, o maaya ${ }^{1}$, es un caso único por su larga historia de escritura y literatura. Se sabe que su forma escrita ha existido por más de un milenio; se escribía con glifos antes de la llegada de los europeos y durante cinco siglos ha empleado grafías del alfabeto latino. Aunque la tradición de la escritura fue interrumpida y suprimida a partir del siglo XVI, nunca se extinguió por completo. En las últimas décadas la cultura y el idioma, así como su escritura, han gozado de una revalorización social. Cada vez hay más publicaciones en maaya y el programa de educación intercultural bilingüe en las escuelas sigue extendiéndose. Este artículo presenta una vista panorámica del estatus actual del maaya escrito, incluyendo un análisis de la situación y una especulación sobre su desarrollo futuro. La investigación se llevó a cabo durante 2001-2002 y constó de un examen minucioso de todas las publicaciones en lengua maaya a mi alcance así como entrevistas y pláticas informales con una docena de escritores, educadores, administradores y maayahablantes.

Antes de examinar el maaya escrito en la actualidad es importante considerar brevemente algunos antecedentes, específicamente las tres obras de descripción de la gramática del maaya que fueron producidas en español por los frailes durante el periodo colonial: Arte en lengua de maya, por Juan Coronel, publicada en 1620; Arte de lengua maya, escrita por Gabriel de San Buenaventura y publicada en 1684; y Arte del idioma maya reducido a sucintas reglas, y semilexicón yucateco de Pedro Beltrán de Santa Rosa, publicada en 1746.

Estas tres gramáticas fueron creadas como herramientas pedagógicas para los misioneros españoles y son especialmente importantes ya que la política oficial de la Iglesia durante los primeros siglos de la colonización obligaba a que los esfuerzos de la evangelización se rea-

\footnotetext{
${ }^{1}$ Este idioma es llamado por sus hablantes y otros yucatecos como maaya; en la escritura académica suele nombrarse maya yucateco o maya peninsular, para distinguirlo dentro de la familia de treinta lenguas y culturas mayas que existen en Mesoamérica. Este artículo emplea el término maaya para referirse al idioma hablado en la península de Yucatán, y maya para designar a la familia lingüística.
}

lizaran en lenguas indígenas del Nuevo Mundo. Es necesario considerar actualmente estas obras porque aún contribuyen al proceso de desarrollo del maaya escrito de dos maneras importantes: en primer lugar, es muy conocido que el maaya cuenta con una larga historia como tema de interés académico, la cual contribuye al carácter actual del idioma y acrecienta su capital simbólico. En segundo término, del siglo XVI al XIX, y en menor medida en el XX, cada una de las subsecuentes gramáticas se basaron en las gramáticas producidas con anterioridad. Siguiendo la costumbre de la época, los autores intentaron explicar el maaya de acuerdo con los tiempos y otros rasgos de la gramática del latín y posteriormente del español. Un resultado de esta práctica es que los antiguos marcos teóricos fueron reproducidos, arraigándose en la práctica académica hasta nuestros días.

Este artículo examina el estatus actual del maaya escrito mediante: a) una amplia revisión de los materiales escritos existentes, sus autores y sus lectores; y b) la descripción de las condiciones sociales que contribuyen al desarrollo del lenguaje escrito. Existen tres factores importantes que operan en todos los actores (escritores, lectores, no lectores, educadores, editores, y corpus literario en sí). En primer lugar, el español tiene influencia no sólo como un conjunto de normas y costumbres, sino también como símbolo y ejercicio de poder. El segundo factor es la situación actual de crisis económica en la península, que limita los proyectos y esfuerzos sociales que no brindan beneficios económicos de manera directa. Finalmente, a pesar de que la lengua y cultura maya yucateca gozan actualmente de una gran revalorización y que la alfabetización en español es considerada importante, la alfabetización dual (español-maya) generalmente no se percibe como algo primordial o deseable.

Otros dos elementos afectan de manera más directa la forma del maaya escrito. Es sobresaliente que las publicaciones actuales estén orientadas hacia una audiencia de aprendices, y que todas entren, hasta cierto punto, dentro del marco del español. A pesar de estos inconvenientes, muchas personas se muestran optimistas ante un desarrollo a largo plazo del maaya escrito.

Podría decirse que existen más publicaciones en maaya en la actualidad que en cualquier momento de los últi- 
mos 500 años, y que indudablemente son más las personas que ahora están escribiendo en dicha lengua. La cantidad de publicaciones continúa incrementándose tanto como la revalorización de la lengua y la cultura. Las instituciones educativas y culturales están cada vez más involucradas en la escritura y continúan financiando proyectos de publicación de diversos tipos. Desde el año 2000, por ejemplo, en Yucatán se emiten dos convocatorias anuales de concursos en maaya: uno de poesía y otro de cuento corto. Estos eventos reciben cierta publicidad y como premio una cantidad importante de dinero. Un concurso anual de la canción en lengua maaya inició en el año 2002. Sin embargo, cabe mencionar que este florecimiento está casi por completo enmarcado dentro de las "bellas artes" y no en trabajos de ciencia o ensayo. Para entender el estatus del maaya escrito debemos tomar en cuenta lo que se está escribiendo y/o publicando, quiénes son sus autores y a qué tipo de públicos va orientado.

\section{AUDIENCIAS}

Primero vamos a considerar la audiencia. Existen tres tipos de público para las publicaciones actuales, dos de las cuales están dirigidas a los aprendices. El más pequeño de los tres grupos es, en gran medida, el de los mayahablantes que saben leer y escribir en maya. El segundo grupo lo integran los hablantes de maaya (niños y adultos) que están siendo alfabetizados en ese idioma; el tercer grupo lo constituyen los no hablantes alfabetos - personas de patrimonio maaya y personas ajenas. La gran mayoría de las publicaciones en maaya se producen con la intención explícita de facilitar la lectura a una audiencia de lectores que no maneja la lengua fluidamente, hablantes que adquieren las habilidades de la lectura o no hablantes que aprenden la lengua. No debe sorprendernos que los escritos para estas audiencias proporcionen indicaciones contextuales y más entradas simples y directas que lo harían para hablantes/lectores que ya saben leer y escribir el idioma. Ante la ausencia de normas y costumbres establecidas para la lengua escrita, el material orientado a principiantes está fijando los preceden- tes normativos que seguramente afectarán en un futuro la forma del maaya escrito. Si estas pistas e indicaciones contextuales se volvieran normas de la buena escritura en todos los géneros, podría resultar un sistema engorroso y poco elegante, con la consecuencia de desalentar a la gente de participar en la práctica de la lectura/escritura ${ }^{2}$.

\section{PUBLICACIONES}

Podemos catalogar las publicaciones actuales tal como se bosqueja en la figura 1 (p. 278) $)^{3}$. Los tipos de documentos se dividen en tres ramas: 1) libros y folletos, 2) periódicos y revistas, y 3 ) documentos oficiales. Los libros y folletos publicados a partir de 1980 se pueden dividir en tres categorías importantes: 1) materiales y herramientas pedagógicas de la alfabetización (libros de texto, cartillas para niños, diccionarios y glosarios); 2) trabajos literarios (cuentos creados para niños y para todo público, poemas, leyendas tradicionales, rezos tradicionales mayas y proverbios), y 3 ) historias (etnografías, memorias, acontecimientos biográficos y publicaciones o reediciones de documentos históricos).

Aunque he examinado una variedad de traducciones antiguas y publicaciones contemporáneas en maaya de documentos religiosos y litúrgicos cristianos, los excluyo ahora de este análisis principalmente porque no tienen como finalidad la expresión, la práctica, el mantenimiento de la lengua y de la cultura maya. Además, se han publicado en su mayoría sin ninguna explicación de cómo, cuándo y quién se hizo cargo de las traducciones. Algunas son obviamente, por su alfabeto y ortografía, republicaciones de traducciones anteriores, mientras que otras parecen ser más recientes; sin embargo, esto es muy difícil de comprobar.

\footnotetext{
${ }^{2}$ Abordando esa situación, Pfeiler (1997) sugiere que para la literatura en general la representación de las vocales con sólo dos formas, a y $a a$, serían suficientes. En contraste, hay cinco formas en el alfabeto de 1984: $a$, aa, áa, a’a y $a$ '.

${ }^{3}$ Para un informe detallado de publicaciones en maaya, véanse Antochiw, 1996 (siglos XVI al XX) y Ligorred Peramon, 1997 (obras literarias contemporáneas).
} 


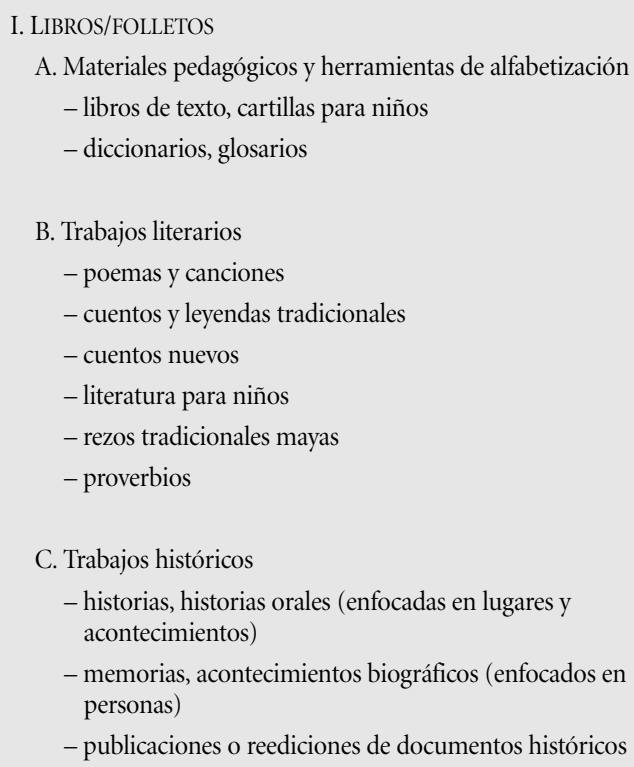

II. PERIÓDICOS Y REVISTAS

A. Literarios, ediciones especiales de revistas en maaya

- cuentos cortos

B. Populares, publicaciones eventuales o temáticas

- editoriales/artículos sobre política

- artículos históricos

- poemas, cuentos cortos

- cartelera de eventos locales, páginas de sociales

\section{DOCUMENTOS OFICIALES}

- códigos legales

- panfletos, materiales al servicio de agencias públicas

- materiales diversos del servicio público.

Figura 1. Categorías de las actuales publicaciones en maaya.

Existe una Biblia en maaya, producida por grupos protestantes. Según un informante bien documentado, la Iglesia católica no favorece la lectura de esta Biblia, presumiblemente a causa de su procedencia protestante. Con base en mi experiencia personal y en entrevistas hechas a colegas yucatecos, he podido concluir que esta Biblia

sólo se lee ocasionalmente. Mucha gente que desearía leerla no puede porque carece de las habilidades indispensables de la lectoescritura; otros que han intentado leerla se desaniman porque no están acostumbrados al registro de palabras inusuales y literarias, así como oraciones complicadas. En dos hogares me mostraron su Biblia con orgullo, pero también me confesaron que nadie en la familia la había leído. De hecho, puede haber un importante capital cultural en la existencia y la propiedad de esta Biblia; sin embargo, como documento que establece y/o refuerza las normas y las convenciones de la lengua escrita, yo argumentaría que ejerce muy poca influencia.

Las publicaciones periódicas impresas, principalmente las mensuales o bimensuales, se originaron por doquier y duraron solamente algunas ediciones (U Jajil Maaya T'aan, 1986-1987, editada por el Instituto Estatal para la Educación de los Adultos de Quintana Roo; $U$ K'aayil Maya T'aan, 1988-1990, editada por el Instituto Cultural de Yucatán). Son generalmente de interés y distribución local. No he podido ver todas las publicaciones de cuya existencia me he enterado y seguramente hay otras que no descubrí. Tienden a ser bastante similares en su formato; contienen poemas, historias cortas, artículos históricos, editoriales y noticias de acontecimientos culturales locales. También incluyen fotos periodísticas y artísticas, dibujos y otros atractivos elementos gráficos. Un periódico, Nikte' T'aan, se publica actualmente en una edición en línea así como en revista periódica impresa ${ }^{4}$.

\section{MATERIALES PEDAGÓGICOS $Y$ HERRAMIENTAS DE ALFABETIZACIÓN}

Con mucho, la categoría más grande de publicaciones es la de materiales pedagógicos. Desde el primer contacto con los españoles, los no mayas han escrito y publicado gramáticas para la enseñanza del maaya. Del siglo XVI al $\mathrm{XX}$, algunas de estas obras fueron producidas para el cle-

\footnotetext{
${ }^{4}$ Nikte' T'aan (previamente Nicte T'an) se encuentra en <http://
} www.carrillopuerto.net/niktetaan/left.html>. 
ro y los misioneros (Coronel, 1620 [1998]; Beltrán, 1742 [1869], por ejemplo); en el siglo XX, los lingüistas y otros académicos comenzaron a involucrarse en esta labor. Estos trabajos continúan publicándose, principalmente para una audiencia extranjera. En las dos últimas décadas las gramáticas y los textos para aprender maaya se han producido para nuevos lectores: no hablantes de patrimonio maya y yucatecos no mayas (no misioneros). Algunas publicaciones están diseñadas como libros de texto para clases de maaya para adultos que se imparten en muchos lugares, mientras que otras son para uso autodidáctico. El incremento de este tipo de audiencia se puede atribuir directamente a la revalorización de la lengua y de la cultura en general. Muchos lectores/usuarios de estos textos no tienen como principal propósito leer literatura maaya. El uso de la lengua escrita es estrictamente instrumental; es decir, la lectura de textos es simplemente un medio, su última meta es poder conversar en maya. Una percepción común entre yucatecos, que ratifiqué en mis entrevistas y conversaciones ocasionales, es que el aprendizaje de una segunda lengua, particularmente en los adultos, no se puede lograr sin la ayuda de la lecto-escritura.

La educación intercultural bilingüe ha sido oficialmente autorizada en los niveles estatales y federales, y varios textos de educación primaria (oficiales y no oficiales) en maaya han sido producidos para niños maaya-hablantes. El estado de Yucatán también tiene un programa de Ko'one'ex kanik maaya (Vamos a aprender maaya) para las escuelas primarias en áreas del estado donde el español es dominante (una serie de textos está siendo desarrollada para dicho programa). Actualmente la universidad estatal ofrece cursos de maaya como un requisito en los programas de las carreras de enfermería, educación $y$ veterinaria, y existen planes de incorporar a otras carreras más. En estos cursos se emplean textos escritos por sus profesores o publicados por la universidad, disponibles para todo público. El español es la lengua principal de estos textos y todas las explicaciones e instrucciones están dadas en español.

\section{Textos para aprender maaya}

Examiné siete textos para aprender maaya, publicados entre 1982 y 2002, que se muestran en orden cronológico en el cuadro 1. Las primeras tres columnas presentan al autor o institución que preparó el texto, el título del texto y la fecha de publicación. En la cuarta columna se indica a qué público está dirigido el texto de acuerdo con lo dicho en su prefacio o introducción. La quinta columna da la categoría del método utilizado: comunicativo (orientado hacia la plática), análisis gramatical o listas de vocablos.

En todos los casos los textos fueron pensados para una audiencia de no hablantes. A excepción del Curso de lengua maya para investigadores, se presupone que son para los residentes de la península, y por lo tanto para gente

Cuadro 1. Audiencia y enfoque de los siete textos más recientes sobre lengua maaya

\begin{tabular}{|c|c|c|c|c|}
\hline Autor/Institución & Título & Fecha & Audiencia & Método \\
\hline $\begin{array}{l}\text { Eduardo Medina } \\
\text { y Javier Gómez }\end{array}$ & $\begin{array}{l}\text { Método para el aprendizaje } \\
\text { de la lengua maya }\end{array}$ & 1982 & general (sin especificar) & vocabulario \\
\hline SEP Yucatán & Ko'one'ex Kanik Maaya & 1993 & grados 3-6 & comunicativo \\
\hline Hilaria Máas & Curso de lengua maya para investigadores & $1997-1999$ & $\begin{array}{l}\text { investigadores locales } \\
\text { y extranjeros }\end{array}$ & análisis gramatical \\
\hline $\begin{array}{l}\text { Cessia Chuc y } \\
\text { María Teresa Doñate }\end{array}$ & Yáax xooki ich maya & 1998 & $\begin{array}{l}\text { estudiantes universitarios } \\
\text { y profesionales }\end{array}$ & análisis gramatical \\
\hline Ismael May & Ko'ox tsikbal & 2000 & estudiantes de la academia & comunicativo \\
\hline Ismael May & $\begin{array}{l}\text { Kan Maaya yéetel } \\
\text { ejen tsikbalo'ob }\end{array}$ & 2002 & $\begin{array}{l}\text { aprendices de maaya } \\
\text { como segunda lengua }\end{array}$ & comunicativo \\
\hline Javier Gómez & Maaya T'aan Junp'éel & 2002 & estudiantes universitarios & comunicativo \\
\hline
\end{tabular}




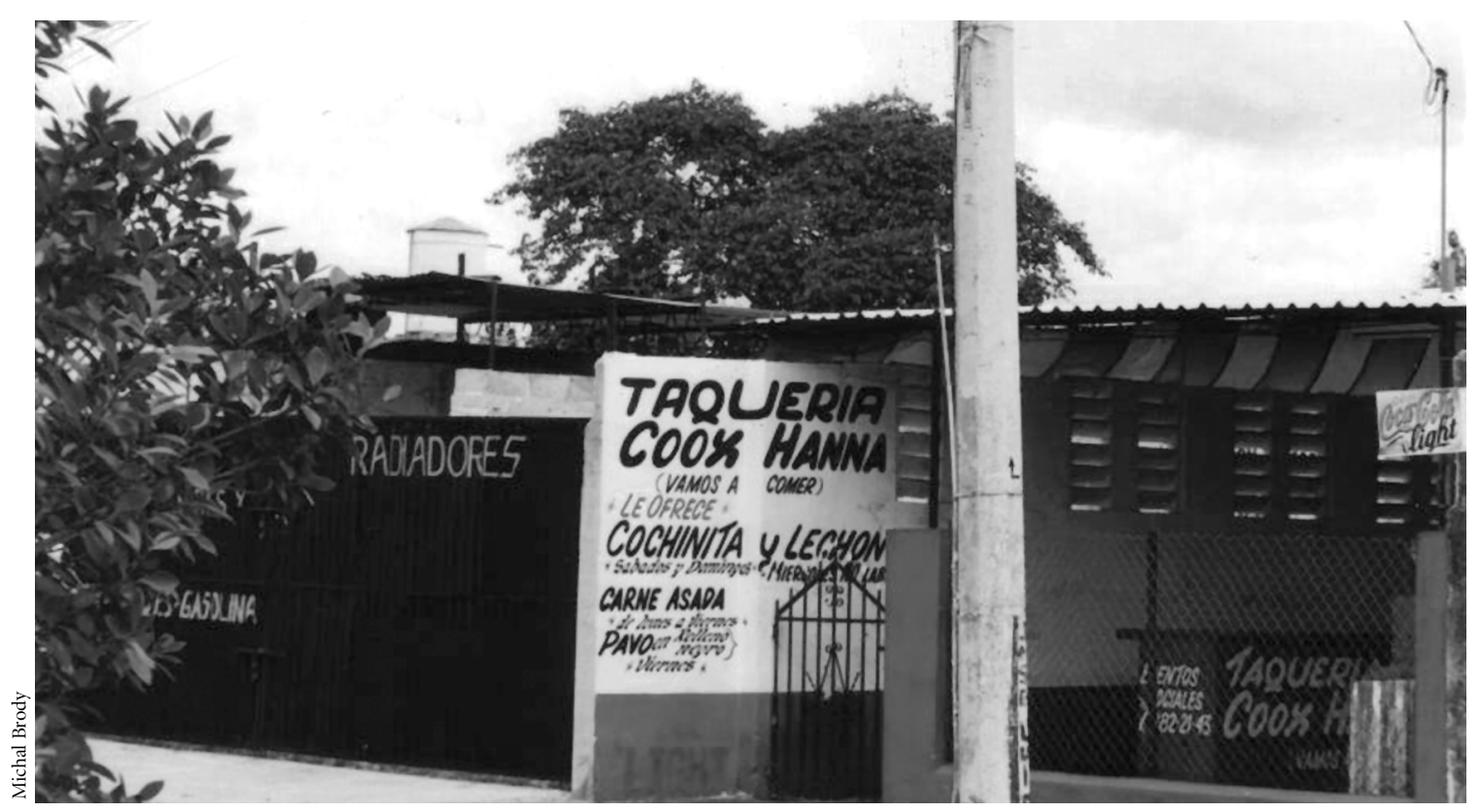

Valladolid, Yucatán.

que tiene cierta familiaridad con la lengua. En el cuadro, la información sobre el tipo de audiencias fue tomada de los libros mismos. Tres fueron publicados para su uso en clases en la universidad y para ser utilizados en clases de maaya como segunda lengua para grados de tercero a sexto de la escuela primaria. El texto Ko'ox tsikbal fue producido por un instructor de la academia municipal en Mérida para servirse de él en sus propias clases para principiantes. Los dos textos restantes pueden ser usados en clase, aunque no fueron diseñados para su uso en el aula. El más antiguo de los siete, escrito por Medina y Gómez, tiene como propósito establecer para sus lectores una conexión con sus raíces étnicas y proteger, así, la continuidad de una gran cultura. Ismael May, autor del segundo texto, señala que su libro es considerado como un recurso auxiliar para aquellos que estén estudiando maaya como segunda lengua.

Cuatro de los siete libros adoptan lo que podría ser un cierto tipo de enfoque comunicativo; es decir, se organizan alrededor de diálogos simples. Tres de ellos (el texto de educación primaria Ko'one'ex kanik maaya; el de la universidad, Maaya t'aan junp'éel; y Ko'ox tsikbal) usan diálogos apoyados por listas de vocabulario y explicaciones gramaticales. En todos los casos el contenido se explica y se traduce al español. El cuarto, Kan maaya yéetel mejen tsikbalo’ob, emplea un sistema innovador: más que listas de palabras, vocabularios y explicaciones de estructura gramatical, los diálogos cortos son seguidos por docenas de iteraciones de cada oración con un componente cambiado, para amplificar el vocabulario o demostrar un paradigma inflexional completo; todo el contenido está acompañado por una traducción al español. De esta manera, los lectores pueden comparar oraciones y hacer inferencias sobre cambios de persona, aspecto, número, etcétera.

Los dos textos universitarios, Curso de lengua maya para investigadores y Yáax xooki ich maya, emplean un enfoque analítico gramatical, presentan paradigmas del pronombre y del verbo, y enmarcan las explicaciones gramaticales en términos de los sistemas gramaticales del español, lengua matriz de los textos. El texto restante, dirigido a todo público, Método para el aprendizaje de la lengua maya, posee un enfoque basado en vocabularios; presenta listas de palabras discretas, semánticamente li- 
gadas (términos de parentesco, animales, etc.) junto con oraciones cortas que contienen las palabras. Curiosamente, los cuatro textos de enfoque comunicativo, más un texto de gramática, tienen títulos en maaya. Aunque Maaya t'aan junp'éel tiene un enfoque gramatical, su objetivo principal, según se indica en la introducción, es facilitar la adquisición de la capacidad comunicativa. Una característica muy interesante de este libro es que explica el inventario de fonemas con el uso de un recurso muy familiar a los estudiantes de lingüística — dibujos de secciones sagitales. Los dibujos de Gómez pueden reconocerse por sus rasgos mayas; un ejemplo se muestra en la figura 2.

\section{Diccionarios}

Hasta la fecha sólo ha existido un diccionario monolingüe de maaya, escrito por Santiago Pacheco Cruz (18851970), que nunca tuvo buena aceptación y del que se publicaron pocos ejemplares en 1969. Pacheco Cruz no es de origen maya. Fue un escritor prolífico en la lengua, pero se dice que asumió un carácter paternalista y que se comportaba de manera arrogante y superior hacia los mayas. Aunque el diccionario es principalmente monolingüe, con definiciones en maaya, contiene más de treinta páginas preliminares en español: introducción, dedicatoria, explicación del uso, etc. Además, muchas de las mismas definiciones contienen, al margen, largos comentarios en español.

El diccionario más prominente de maaya (maaya-español) en los tiempos modernos fue publicado originalmente en 1980 (Barrera Vásquez et al., 1980). Conocido como Diccionario Cordemex, nombre de la entonces compañía henequenera que financió su publicación, el diccionario es un compendio de todos los diccionarios y glosarios anteriores desde el siglo XVI. El enorme volumen contiene casi 1400 páginas y pesa más de cinco kilos. El proyecto de compilación fue dirigido por Alfredo Barrera Vásquez, y su meta era proporcionar una herramienta para el desciframiento de los glifos y la interpretación de los textos producidos durante el periodo colonial. Barrera Vásquez y sus colaboradores establecieron el alfabeto

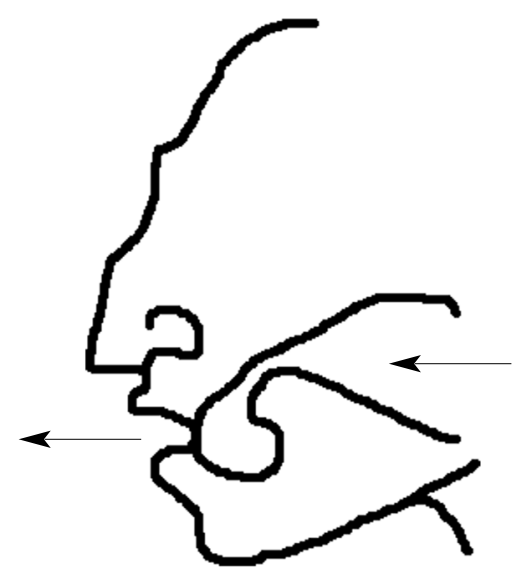

Figura 2. Sección sagital que muestra la posición de los articuladores orales en la producción de [š], el sonido que se escribe sh en inglés (Gómez, 2002).

que se utilizaría en el proyecto con el criterio principal de ser fácilmente producido con la tecnología existente, es decir, con máquinas de escribir. Este alfabeto influyó enormemente en las reuniones llevadas a cabo en la década de 1980 para adoptar u oficializar el alfabeto.

Dos pequeños diccionarios de maaya (maya-español) de bajo costo fueron publicados en la década de 1990, pensados para el uso cotidiano de estudiantes y público en general. Uno, conocido como "el Verdecito", por el color de su cubierta, fue publicado por primera vez en 1992 por un editor comercial; algunas ediciones subsecuentes fueron parcialmente financiadas por el gobierno. Este diccionario fue compilado por el antropólogo Juan R. Bastarrachea, que también colaboró en el Diccionario Cordemex, junto con Ermilo Yah Pech y el lingüista Fidencio Briceño Chel. Toda la explicación del diccionario está dada en español. Es muy coloquial en su estilo y contiene una sección español-maaya seguida por otra sección maaya-español de igual proporción. Las entradas dan la categoría gramatical, el género de los sustantivos en español, así como tres equivalentes léxicos para cada entrada y/o paráfrasis cuando es necesario. El hecho de que se señale el género del sustantivo (en vez de darlo por conocido) sugiere que el diccionario fue pensado para ser de utilidad tanto para los hablantes de maaya que están aprendiendo español como para los hablantes de español que están aprendiendo maaya. 
En 1997, el Instituto Nacional para la Educación de los Adultos (INEA) en Yucatán, dependiente de la Secretaría de Educación Pública, publicó el Diccionario de la lengua maya (maya-español), conocido como el Diccionario del INEA o el Diccionario amarillo, para distinguirlo del verde. Este diccionario sigue un formato similar al anterior en el que explica, sólo en español, el alfabeto y la ortografía del maaya. Contiene una sección breve, pero muy útil, en la que menciona los prefijos y los sufijos (inflexionales y derivados) comunes del maaya, además de un breve apartado muy superficial sobre tiempos verbales en maya ${ }^{5}$. El grueso del diccionario es la sección maaya-español, en la que cada entrada da la categoría gramatical, la transitividad o intransitividad de los verbos (parte muy importante de la gramática), y uno o más ejemplos de frases u oraciones con traducción al español. La sección español-maaya es más corta y sólo da uno o dos equivalentes léxicos para cada entrada. El propósito, indicado en el diccionario, es ser una herramienta para los "educadores bilingües y otros que colaboran con el programa de alfabetización a la población indígena" los estudiantes o qué lengua(s) puede(n) hablar.

Un diccionario nuevo, más sustancial, producto de un largo proyecto de la Academia de Lengua Maya A. C. ${ }^{6}$, apareció en 2003. Este diccionario es muy detallado y está considerado como muy bueno, aunque es mucho más costoso, lo que lo deja fuera del alcance de muchos usuarios potenciales. En el año 2000, un vocabulario trilingüe maaya/español/inglés fue publicado por el Centro de Estudios del Mundo Maya; en parte se asume que es para aprovechar el mercado turístico angloparlante, y también, quizás, para aprovechar el prestigio del que goza el inglés entre los yucatecos, muchos de los cuales trabajan parte del año en Cancún o en otros centros turísticos de la península, donde saber inglés es muy útil y rentable.

\footnotetext{
${ }^{5}$ Casi todas las obras pensadas para quienes no son lingüistas describen los tiempos maayas a pesar de que, en cuanto a la lingüística, el idioma no cuenta con tiempos, sino con aspectos. Claramente el maaya se está interpretando a través de la lente del español y/o de otros idiomas europeos.

${ }^{6}$ Esta academia es una organización civil y no se asocia de ninguna manera con la Academia Municipal Itzamna de Lengua Maya en Mérida, Yucatán.
}

\section{ESCRITORES}

Podemos establecer una sola generalización que caracteriza a todos los escritores contemporáneos de maaya, significativa de hecho. Fueron escolarizados mediante programas educativos en español y este idioma fue la primera lengua de lectoescritura para casi todos ellos, a pesar de que el maaya fue su lengua materna ${ }^{7}$. Por eso, las reglas, normas y la lógica del español escrito tuvieron mucha influencia en ellos. Aparte de este rasgo común y del orgullo compartido de su lengua y cultura, conforman un grupo diverso. De los escritores que conozco, no todos asistieron a la universidad. Encontramos mujeres y hombres, jóvenes y adultos, de origen rural y urbano.

En 1982 se inició un taller de literatura maaya y, desde entonces, varios más han tenido lugar en diversos momentos y lugares. En dichos talleres los hablantes que escriben, o aspiran a escribir, se reúnen en sesiones para desarrollar y motivar la escritura del maaya y para abordar temas específicos como poesía, sintaxis o traducción. Estos talleres se diseñan a menudo específicamente para gente joven. Además, algunos escritores yucatecos, encargados de los talleres, son miembros activos de una organización nacional de escritores en lenguas indígenas y han pugnado por los derechos lingüísticos de las comunidades indígenas.

\section{ENMARCAR EN ESPAÑOL}

Una característica esencial a todas las publicaciones de maaya es el papel que desempeña el español en ellas. En primer lugar, la inmensa mayoría de las publicaciones son bilingües, es decir, que el material es presentado en maaya y en español, a veces en la misma página y otras, aunque de manera menos frecuente, se presenta secuen-

\footnotetext{
${ }^{7}$ Hay informes confiables sobre que una tradición continua del maaya escrito se ha mantenido y se ha protegido entre individuos selectos en algunas de las comunidades del este de la península (Grube, comunicación personal, entre otros). Por razones obvias, esta tradición tiene una base "subterránea". No conozco a ninguno de estos escritores ni he visto sus documentos; por lo tanto, no se incluyen en esta investigación.
} 
cialmente, o sea, primero la versión completa en maaya seguida de la versión en español. La serie Maaya ts'iibo'b bejla'e / Letras mayas contemporáneas —el proyecto editorial más ambicioso de maaya hasta la fecha- sigue un formato diferente a otras ediciones bilingües. Cada trabajo se publica en dos volúmenes separados: uno en maaya y el otro en español. Fue editada por el escritor Carlos Montemayor y publicada por dos instituciones federales: el Instituto Nacional Indigenista (INI) y la Secretaría de Desarrollo Social (Sedesol), con el apoyo financiero de la fundación Rockefeller ${ }^{8}$. Se han publicado tres series separadas de estas obras. La primera consta de cuarenta volúmenes y son trabajos hechos en maaya. La segunda serie se centra en los idiomas mayas de Chiapas; y la tercera cuenta con quince volúmenes, hasta la fecha, con trabajos en maaya y lenguas mayas de Chiapas. Con excepción de un libro de la serie de maaya, los demás fueron publicados por pares. La excepción es una guía pedagógica para los profesores bilingües de escuelas primarias, que incluye ejercicios y ejemplos; este libro sólo se editó en maaya (M. May May, 1998). Además de éste, he encontrado sólo un libro escrito totalmente en maaya; se trata de una colección de cartas escritas por y para líderes militares mayas y otras personas durante la denominada Guerra de Castas del siglo XIX. Tanto la introducción como el prefacio están redactados en maaya (Dzul Polanco et al., 1995).

El hecho de que las publicaciones en maaya estén concebidas casi siempre como bilingües ratifica el estatus subordinado del maaya escrito, incluso en el mismo medio previsto para promover su revalorización. Un elemento adicional que refuerza el estatus de segunda clase de la lengua escrita es el hecho de que todos los libros en maya, incluyendo los pocos que no son bilingües, tiene por lo menos dos elementos que se imprimen solamente en español: el copyright y el colofón 9 . Aunque la pági-

\footnotetext{
${ }^{8}$ Cabe señalar que los libros de estas series fueron financiados con la estipulación de que se distribuyeran sin carga y de no estar disponibles para la venta. De hecho, nunca he visto que se vendan en México ni en Estados Unidos (tampoco en la subasta de internet, e-bay).

9 La página del colofón, una costumbre en las publicaciones de América Latina y otras partes del mundo, es la página final del libro en la
}

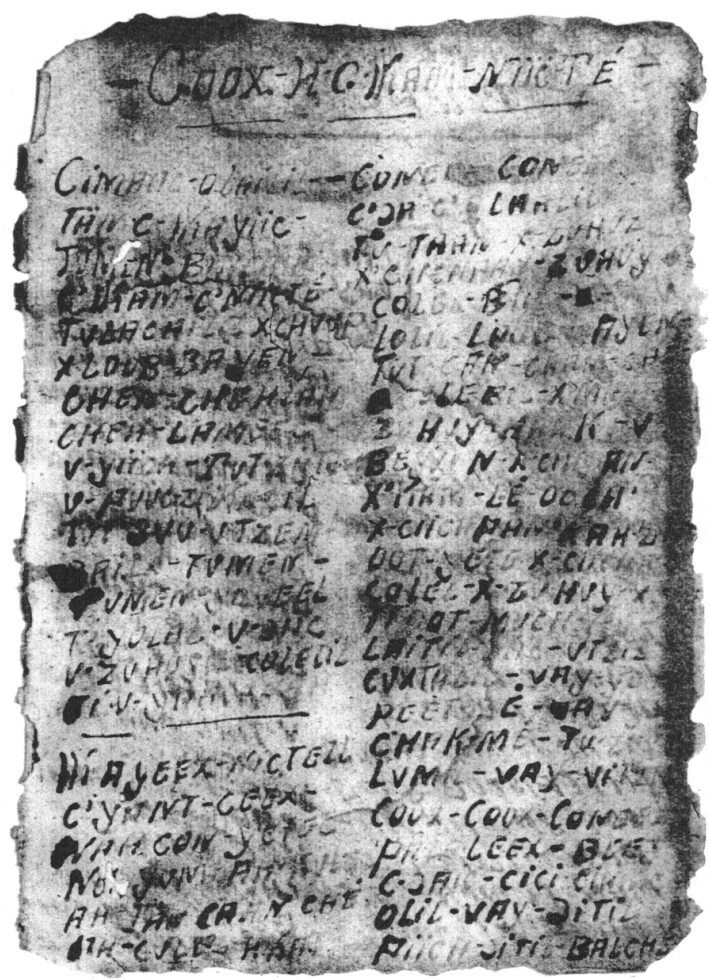

Los cantares de Dzitbalche, ca. 1750. Es un documento en maaya peculiar por estar escrito en letras de molde.

na del copyright es obligatoria, no es un requisito legal y, según mis fuentes, que la información contenida en ella se dé en español es simplemente una cuestión de costumbre. Un escritor especuló que algunas editoriales pueden asumir simplemente que, dado que el español es la lengua oficial del país, sería requerido para esas dos páginas. Es curioso observar, sin embargo, que en todos los títulos en maaya y en español de la serie Letras mayas contemporáneas antes mencionada, hay un renglón en la página del copyright que dice en inglés: "Printed in Mexico" (impreso en México), posiblemente como un pequeño reconocimiento a la ayuda otorgada por la fundación Rockefeller a la serie.

Otros elementos preliminares suelen estar en español. Los prólogos y las introducciones de las colecciones bi-

que se proporciona el nombre de la imprenta, fecha de producción y, generalmente, el tiro o número de ejemplares producidos. 
lingües están a menudo en español. Como señalé antes, los dos diccionarios bilingües recientes dirigidos al público en general (más que para los especialistas) contienen explicaciones para su uso y la introducción solamente en español. Las portadas y las contraportadas de libros suelen ser bilingües; la información publicitaria, sin embargo, raramente tiene contenido en maaya.

Así vemos que los libros en maaya están generalmente enmarcados en su principio y fin en español, y no se sustentan por sí mismos. Supongo que este encuadre es resultado de dos factores: primero, la escritura del maaya tiene una función limitada como medio de la cultura tradicional. Es apropiado para la descripción de costumbres, para creaciones ingeniosas y para presentar información histórica, especialmente aquella que fue originalmente captada de manera oral (como entrevistas o historias orales). El maaya, sin embargo, todavía no se percibe, al parecer, como apropiado para los negocios del mundo moderno (por ejemplo, industria editorial o derechos de autor). Además, como ya se señaló, la gama de géneros apropiados para el maaya escrito se restringe a trabajos más literarios o humanistas, y no para los negocios, la ciencia y la tecnología. Segundo, puede ser que la existencia de publicaciones cien por ciento en maaya pudiera amenazar el status quo lingüístico. La diversidad lingüistica y cultural se considera actualmente como algo favorable, oficialmente y en la conciencia nacional actual, pero las publicaciones cien porciento en maaya podrían ser percibidas como esfuerzos por desplazar - más que por complementar — la lengua nacional.

\section{DISTRIBUCIÓN}

Hemos visto que el número de publicaciones en maaya se está incrementando y que se están produciendo más y más publicaciones de varios tipos, pero la distribución aún representa un problema serio. Tomando en cuenta que muchos hablantes y/o lectores de maaya no pueden permitirse comprar libros, muchas publicaciones con financiamiento institucional (las cuales son la gran mayoría) son hechas para ser distribuidas sin ningún costo en las comunidades mayas yucatecas, aunque en realidad hay poca disposición para organizar una red eficaz de distribución. Más de un informante me confió los pormenores de los problemas con la distribución. Muchos proyectos de publicación fueron financiados por más de una institución y, en algunos casos, la responsabilidad de la distribución nunca se hizo explícita; así, ninguna institución adquirió el compromiso de asegurarse de que las publicaciones fueran distribuidas. En otros casos, la distribución gratuita en comunidades de la península fue una condición del apoyo institucional otorgado. De esta manera, aunque la demanda comercial puede existir para determinadas publicaciones, éstas nunca aparecen en librerías ni son vendidas a bibliotecas interesadas. Las remesas de libros se almacenan en lugares donde no pueden ser mantenidas indefinidamente en condiciones usables debido al clima caluroso y húmedo de la península. Leirana (1998) confirma los problemas con la distribución y también cuenta varios casos en los que las editoriales habían engañado a los autores con el pago de sus regalías.

Los libros de textos de la escuela primaria antes mencionados se han producido en gran cantidad, pero es muy conocido que esos textos nunca han llegado a muchas de las escuelas para las que fueron creados. Los mismos funcionarios de la Secretaría de Educación Pública se muestran perplejos ante el problema, y algunos me expresaron su frustración por esta situación. También indicaron que incluso en algunas de las escuelas donde los libros estaban ya en manos de los estudiantes, los profesores no sabían ni deseaban utilizarlos.

\section{ALFABETIZACIÓN Y PROGRAMAS DE ALFABETIZACIÓN PARA ADULTOS}

El desarrollo de una literatura —que en su sentido más amplio incluiría cualquier caso del lenguaje escrito- depende no solamente de la producción de publicaciones, sino también de un cuerpo de lectores capaces. Sólo una proporción relativamente pequeña de maayahablantes cabe en esa categoría, pues en gran medida la instrucción en maaya hasta muy recientemente ha sido poco desarrollada e infravalorada. Además, la añeja tradición de la escritura y las prácticas de la alfabetización habían esta- 
do siempre en manos de una élite; el concepto de educación universal llegó a ser importante apenas hasta hace poco tiempo. La situación representa un círculo vicioso, en el cual mucha gente cree que no tiene caso aprender a leer maaya cuando existe tan poco material para leer $y$, al mismo tiempo, los proyectos de publicación pueden carecer de ayuda por la cantidad tan restringida de lectores potenciales. Los esfuerzos hacia el aumento del número de lectores han comenzado en los últimos veinte años y se están incrementando; existen programas tanto para niños como para adultos en varios niveles y grados, y ha habido talleres exitosos de escritura para adultos en varias comunidades.

He escuchado discusiones apasionadas representativas de una diversidad de posiciones. Algunas personas discuten que la instrucción en maaya es insustancial y que la instrucción en español es mucho más importante, ya que puede contribuir a su sustento, mientras que otras personas opinan que la alfabetización en maaya debe hacerse más accesible porque la supervivencia de la cultura está en juego. La escasez de recursos financieros es siempre un factor a considerar en cualquier asunto de políticas públicas. Aunque algunos lugares gozan de una buena situación económica, la pobreza crónica imperante en toda la península hace que los asuntos y las soluciones económicas inmediatas sean, con toda razón, prioritarios.

A pesar de que poco más de 90\% de la población que habla maaya en Yucatán es bilingüe, según los datos del último censo de población, muchos adultos maayahablantes no saben leer y escribir en ninguna lengua $y / o$ no están acostumbrados a utilizar la escritura en la vida cotidiana. Muchos más pueden, por lo menos, leer algo de español aunque creen que sus habilidades de lectoescritura no son automáticamente transferibles al maaya sin cierta instrucción explícita, actitud que noté con frecuencia en conversaciones y entrevistas. Algunas personas me dijeron que el maaya es mucho más difícil de leer que el español, y muchos indicaron que se habían confundido por tantos apóstrofos. Aunque la gran mayoría de la gente que sabe leer y escribir en maaya señaló no tener ningún problema o incomodidad con la variación gráfica u ortográfica que encuentran (de hecho, mi pre- gunta dejó perplejos a algunos), debería investigarse si esta variación desanima a otros lectores o potenciales lectores. Al respecto, King (1994: 148) expone una declaración hecha por un hablante que sabe leer y escribir en maaya:

La lengua maya es realmente difícil de escribir. Estas letras en maya son muy difíciles. Yo vi cuando el profesor discutía con otras dos personas. Un día este profesor hablaba de la escritura maya, y él puso la palabra cax... ['pollo'] en la pizarra, pero el otro profesor tomó la tiza, tachó la $c$ y puso $k$ y puso acento a la a. "Yo sé — dijo él一, tomé clases de escritura en maya." Y entonces discutieron acerca de si debería escribirse con $c$ o con $k$.

Anécdotas como éstas abundan y refuerzan la opinión popular de que el maaya escrito es desalentadoramente difícil; sin embargo, un funcionario del Departamento de Educación con quien hablé dio un punto de vista diferente. Me relató la experiencia de un colega supervisor que fue a visitar una escuela en donde supuestamente se llevaba a cabo un programa bilingüe. Éste encontró a una maestra dando la clase en español, en vez de hacerla en maaya, y cuando preguntó por qué, admitió que la razón estaba en que ella pensaba que enseñar en maaya era demasiado difícil para los niños:

[...] entonces, el supervisor tomó un libro, en maya, que había llevado, y se lo dio a un niño sentado frente al profesor, para que leyera; el niño procuró leerlo, y lo leyó. Él leyó en maya... No es difícil. La dificultad está en la mente del profesor. Los niños tienen creatividad, tienen la capacidad de escribir lo que desean en maya...Y sin saber leer y escribir en maya, han demostrado que sí pueden.

Las estadísticas del INEA en Yucatán también sugieren que la lectura del maaya es una meta alcanzable. El INEA ofrece clases para la alfabetización de los adultos en maaya y en español, así como educación primaria y secundaria para los adultos. Las cifras de atención y egreso a partir del año 2000 se muestran en el cuadro 2 (p. 286). Las cifras anuales para el número total de estudiantes de cada categoría de la clase no están disponibles, pero el número de egresos por año se puede medir como proporción del promedio mensual. De esa manera, la com- 


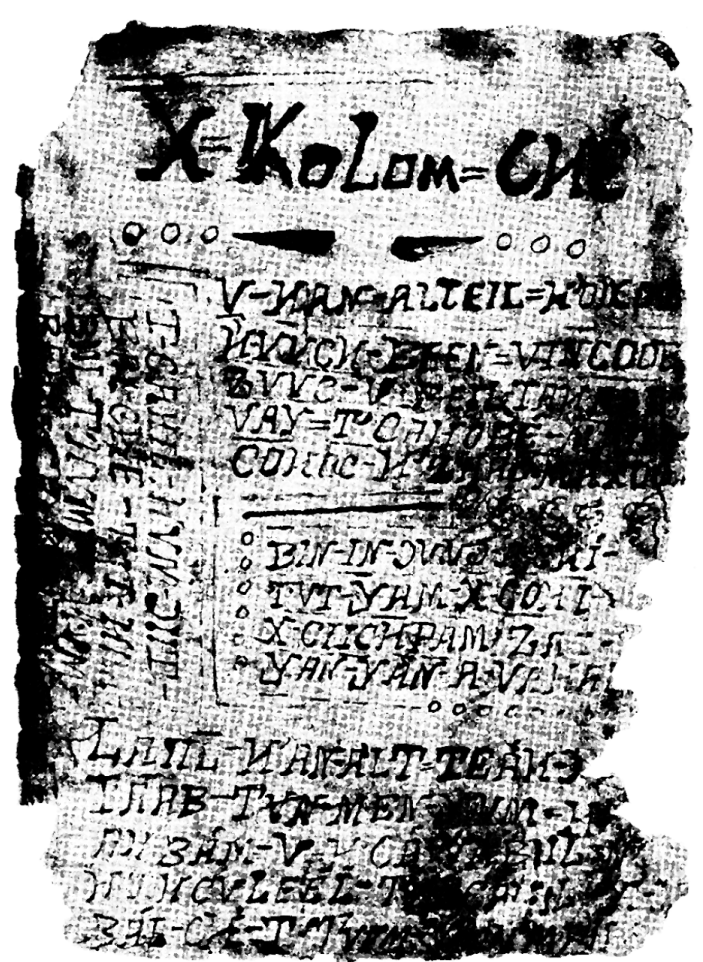

Los cantares de Dzitbalché, ca. 1750.

paración entre la alfabetización en maaya y en español será constante, aunque la cifra resultante reflejará el porcentaje absoluto inexacto de la terminación. Aunque pocos yucatecos se inscriben a clases de maaya (con relación a clases en español), el índice de egresos para el curso de maaya es de $62 \%$, comparado con $58 \%$ en el de español. Si se asume la dificultad del curso y la motivación/esfuerzo del estudiante para ser equivalente, el hecho de que $4 \%$ más de estudiantes termine el curso de maaya que el curso en español sugiere que la complejidad y la dificultad percibidas de la escritura en maaya no es un obstáculo significativo para los principiantes motivados, a pesar del sentir popular.

Vale la pena mencionar la disparidad de la matrícula entre el curso de maaya y el de español. En Yucatán hay aproximadamente diez veces más estudiantes con instrucción en español que estudiantes de maaya; esta proporción varía grandemente de estado a estado. En las otras dos entidades federales de la península, donde la
Cuadro 2. Tasa de asistencia y egresos de los programas de educación para los adultos en Yucatán, 2000 ${ }^{10}$

\begin{tabular}{l|c|c|c}
\hline & $\begin{array}{c}\text { Promedio } \\
\text { de asistencia } \\
\text { mensual }\end{array}$ & $\begin{array}{c}\text { Número } \\
\text { de egresados }\end{array}$ & $\begin{array}{c}\text { Porcentaje } \\
\text { de egresos }\end{array}$ \\
\hline $\begin{array}{l}\text { Alfabetización } \\
\text { (maya) }\end{array}$ & 1416 & 880 & 62 \\
\hline $\begin{array}{l}\text { Alfabetización } \\
\text { (español) }\end{array}$ & 12671 & 7376 & 58 \\
\hline Primaria & 11708 & 3404 & 29 \\
\hline Secundaria & 6308 & 2864 & 45 \\
\hline
\end{tabular}

lengua indígena principal es la maaya, los estudiantes de maaya representan solamente $1.6 \%$ del total de inscritos en Campeche, mientras que en Quintana Roo el porcentaje es de $26.2 \%$. No obstante, el número de estudiantes de maaya en relación con la población total de mayahablantes es bastante constante en los tres estados: 0.3, 0.4 y $0.3 \%$ en Yucatán, Quintana Roo y Campeche, respectivamente, según se muestra en el cuadro 3 , en el que los tres estados peninsulares aparecen sombreados. Esta similitud puede indicar un valor similar, o quizás la devaluación, de la forma escrita de la lengua a través de todo el territorio lingüístico. Por el contrario, en Chiapas, donde el movimiento zapatista por los derechos indígenas es fuerte, un total de $4 \%$ de la población que habla una lengua indígena asiste a clases de alfabetización. Con fines de comparación, el cuadro muestra otros dos estados del sureste mexicano: Oaxaca y Tabasco. En Oaxaca, estado con el segundo porcentaje más alto de hablantes de lenguas indígenas (HLI), $0.7 \%$ tomó clases de alfabetización en lengua indígena —un poco más que los estados en el área de habla maya, pero menos de 1\%. En Tabasco, estado muy urbanizado, con una pequeña población hablante de lengua indígena, sólo $0.2 \%$ de dicha población recibió alfabetización en lengua indígena.

\footnotetext{
${ }^{10}$ Los datos del cuadro 2 proceden de las páginas oficiales del INEA y del INEGI: $<$ http://www.inea.sep.gob.mx/default.htm $>$; $<$ http://www. inegi.gob.mx/difusion/espanol/fietab.html $>$ y $<$ http://hades.inegi. gob.mx/sitio_inegi/estadistica/espanol/sociodem/asentamientos/as e_05.html >.
} 
Cuadro 3. Porcentajes de estudiantes que son alfabetizados en lenguas indígenas (LI) en seis estados del sureste mexicano, 2000

\begin{tabular}{l|c|c|c}
\hline & $\begin{array}{c}\text { \% de hablantes de LI en el total } \\
\text { de la población (< de 5 años) }\end{array}$ & $\begin{array}{c}\text { Número de asistentes a los cursos de } \\
\text { alfabetización en LI por año }\end{array}$ & $\begin{array}{c}\text { \% de hablantes de LI recibiendo } \\
\text { alfabetización en LI }\end{array}$ \\
\hline Chiapas & 21 & 32563 & 4.0 \\
\hline Oaxaca & 33 & 7964 & 0.7 \\
\hline Quintana Roo & 20 & 631 & 0.4 \\
\hline Yucatán & 33 & 1416 & 0.3 \\
\hline Campeche & 14 & 251 & 0.3 \\
\hline Tabasco & 3 & 101 & 0.2 \\
\hline
\end{tabular}

\section{EL MAAYA ESCRITO EN LA EDUCACIÓN PRIMARIA}

Como mencioné anteriormente, existe un programa intercultural bilingüe en el nivel de la escuela primaria para el cual se han elaborado libros de textos. Sin embargo, debido a la escasez de profesores entrenados en el sistema bilingüe, los problemas de distribución con los libros de texto y, según algunos informes, la resistencia al programa en algunas poblaciones, su crecimiento y posibilidades de éxito han sido muy lentos. Investigaciones sobre la adquisición de lectura/escritura en los programas interculturales bilingües están en marcha. Pellicer (1999) hizo la primera investigación sobre las estrategias ortográficas de niños maayahablantes.

Todos los educadores involucrados en el programa con quienes hablé expresaron su optimismo y pusieron énfasis en que aplicar un programa completo de educación bilingüe con éxito es un proceso complicado que requiere de mucho tiempo. Su perspectiva realista combinada con su compromiso sincero crean confianza para el futuro.

\section{SUMARIO}

El estado actual del maaya crea tanto optimismo como pesimismo. Por una parte, los yucatecos se enfrentan a un círculo vicioso. Algunos proyectos de publicación no son financiados o apoyados debido a la falta de lectores letrados y los hablantes, al mismo tiempo, no están convencidos de que valga la pena adquirir la habilidad de la lecto-escritura por el poco material disponible. Pero, por otro lado, existe también un aumento sustancial en el número de publicaciones y una cierta extensión en la variedad de géneros literarios.

Se ha dado un incremento en la ayuda oficial para los programas educativos (educación intercultural bilingüe y maaya como segunda lengua) que podría crear, a corto o largo plazo, una generación de lectores e incrementar la demanda de las publicaciones de literatura en maaya. De manera considerable, sin embargo, el predominio de materiales orientados a los principiantes — diseñados para satisfacer a los lectores que tienen poca fluidez en leer y escribir - influirá probablemente las normas y convenciones - que se encuentran actualmente en una etapa de formación - en formas que pueden no ser deseables a largo plazo.

El papel del español puede también implicar obstáculos a largo plazo para el desarrollo del maaya escrito. La necesidad percibida de producir materiales bilingües más que publicaciones independientes de maaya limita los recursos disponibles (tanto humanos como materiales). Además, el español que enmarca hasta las más monolingües de las publicaciones mayas - títulos, copyright, colofón, y a menudo también las introducciones o los prefacios - refuerza terminantemente el estatus subordinado del maaya escrito. La carencia de publicaciones $100 \%$ en maaya tiene que ver con el hecho de que el maaya escrito se ha restringido en gran parte a los géneros más literarios; también puede deberse a que las publicaciones cien porciento en maaya son percibidas como amenazadoras para el status quo lingüístico. 
La falta de una red de distribución eficaz para las publicaciones también representa un desafío para el desarrollo del maaya escrito. Un hecho más optimista es que los escritores se han organizado para promover la lengua y su literatura. Los escritores mayas yucatecos proceden de todas las regiones del territorio lingüístico y de todos los estratos sociales; esta diversidad de experiencias y voces proporciona una riqueza sin igual. Un funcionario de educación bilingüe me dijo que tan pronto como una generación que ha adquirido el maaya como su primera lengua de lectura y escritura llegue a la edad adulta y comience a escribir y a publicar, el desarrollo de la escritura en maaya florecerá y prosperará.

\section{Bibliografía}

Academia de la Lengua Maya de Yucatán, 2003, Diccionario maya popular, Juan Ramón Bastarrachea Manzano y Jorge Canto Rosado (eds.), Academia de la Lengua Maya, A. C., Mérida.

Antochiw, Michel, 1996, Bibliography of the Mayan Language in Yucatan [Bibliografía yucateca de la lengua maya], Labyrinthos, Lancaster, California.

Barrera Vásquez, Alfredo, Juan Ramon Bastarrachea Manzano y William Brito Sansores, 1980, Diccionario maya Cordemex: maya-español, español-maya, Cordemex, Mérida.

Bastarrachea, Juan, Ermilo Yah Pech y Fidencio Briceño Chel, 1992, Diccionario básico español-maya-español, Maldonado, Mérida.

Beltrán de Santa Rosa, Pedro, 1859 [1746], Arte del idioma maya, Imprenta de J. D. Espinosa, Mérida.

Buenaventura, Gabriel de San, 1888 [1684], Arte de la lengua maya, F. Díaz de León, México.

Centro de Estudios del Mundo Maya, 2000, Vocabulario maya-español-inglés, Centro de Estudios del Mundo Maya, Mérida.

Coronel, Juan, 1998 [1620], Arte en lengua de maya, René Acuña (ed.), Universidad Nacional Autónoma de México, México.

Chuc Uc, Cessia Esther y María Teresa Doñate Gimeno, 1998, Táan kanik maya: Yáax xooki ich maya / Aprendiendo maya: nivel básico, Secretaría de Educación Pública, Fomes, Universidad Autónoma de Campeche, Campeche.

Dzul Polanco, Desiderio Lázaro, Ermilo Yah Pech, Juan Ramón Bastarrachea Manzano, Jorge Manuel Canto Rosado, Fidencio Briceño Chel y Fidelio Quintal Martín, 1995, Maaya ts'íbil ju'uno'ob. 1842..., PACMYC, Mérida.
Gómez Navarrete, Javier, 2002, Maaya t'aan junp'éel: Método para el aprendizaje de la lengua maya, División de Estudios Internacionales y Humanidades, Universidad de Quintana Roo (consultado el 4-II-03 en: <http:// dzibanche.biblos.uqroo.mx/cursos_linea2/javier gomez/cursomaya01.htm>).

Instituto Nacional para la Educación de los Adultos, 1997, Diccionario de la lengua maya, Secretaría de Educación Pública, México.

Instituto Estatal para la Educación de los Adultos de Quintana Roo, 1986-1987, U jajil maaya t'an, Unidad de Culturas Populares Quintana Roo, Chetumal, QRoo.

King, Linda, 1994, Roots of Identity: Language and Literacy in Mexico, Stanford University Press, Stanford, California.

Leirana, Cristina, 1998, "Escritores mayas: ejerciendo su derecho a la diferencia”, Navegaciones Zur, núm. 20, marzo.

Ligorred Pergamon, Francesc, 1997, U mayathanoob ti dzib / Las voces de la escritura, Ediciones de la Universidad Autónoma de Yucatán, Mérida.

Máas Collí, Hilaria, 1997, Curso de lengua maya para investigadores: nivel I, Ediciones de la Universidad Autónoma de Yucatán, Mérida.

__ 1998, Curso de lengua maya para investigadores: nivel III, Ediciones de la Universidad Autónoma de Yucatán, Mérida.

1999, Curso de lengua maya para investigadores: nivel II, Ediciones de la Universidad Autónoma de Yucatán, Mérida.

May May, Ismael, 2000, Ko’ox tsikbal, Ismael May May, Mérida.

__, 2002, Kan maaya yéetel mejen tsikbalo'ob / Aprenda maya con breves diálogos, Programa de Apoyo a las Culturas Municipales y Comunitarias, Mérida.

May May, Miguel, 1998, U pik'ilju’unil u ka'ansa'al xookyéetel dzíib ich maaya, Carlos Montemayor (ed.), Instituto Nacional Indigenista, México (Serie Maya Dziibo’ ob Bejla'e / Letras mayas contemporáneas III, 9).

Medina Loría, Eduardo y Javier Gómez Navarrete, 1982, Método para el aprendizaje de la lengua maya, Instituto para la Cultura y las Artes de Quintana Roo, Chetumal.

Pacheco Cruz, Santiago, 1969, Hahil tzolbichunil t'an mayab / Verdadero diccionario de la lengua maya, Santiago Pacheco Cruz, Mérida.

Pellicer, Alejandra, 1999, Así escriben los niños mayas su lengua materna, Plaza y Valdés, México.

Pfeiler, Barbara Blaha, 1997, "La situación prosódica en el maya y su representación en la escritura”, en María Cecilia Lara Cebada (comp.), Identidades sociales en Yucatán, Universidad Autónoma de Yucatán, Mérida, pp. 231-240.

Secretaría de Educación Pública-Yucatán, 1993, Ko’ox kanik maaya, Secretaría de Educación Pública, Mérida. 